ISSN 1518-3483

Licenciado sob uma Licença Creative Commons

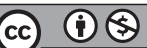

\title{
O Movimento da Matemática Moderna nos boletins da Sociedade Paranaense de Matemática
}

\author{
The New Math Movement in the bulletins \\ of the Sociedade Paranaense de Matemática
}

\begin{abstract}
Alexandra de Oliveira Abdala Cousin
Doutora em Educação Matemática pela Universidade Federal do Paraná (UFPR), Mestre em Matemática pela Universidade Federal do Rio de Janeiro (UFRJ), professora adjunta do Departamento de Matemática da Universidade Estadual de Maringá (UEM), Maringá, PR - Brasil, e-mail: aoacousin@uem.br
\end{abstract}

\section{Resumo}

Neste trabalho apresentamos os artigos publicados nos Boletins da Sociedade Paranaense de Matemática (SPM) que refletem diretamente as influências do Movimento da Matemática Moderna (MMM) no Brasil. Atualmente, esse movimento, de repercussão mundial e que teve reflexos importantes no Brasil, é objeto de nossos estudos. Nossa atenção tem se voltado para as décadas de 1960 e 1970, período quando se verifica sua mais intensa influência na educação básica no Brasil. Apresentamos aqui, numa perspectiva 
histórica, o resultado da busca e análise dos artigos que tratam desse tema que surgiram nas publicações da SPM, mostrando que esse movimento alcançou territórios nacionais importantes, particularmente o Paraná. As fontes utilizadas nessa análise foram todos os boletins editados pela SPM, cobrindo assim um amplo e específico objeto de divulgação.

Palavras-chave: Movimento da Matemática moderna (MMM). Sociedade Paranaense de Matemática (SPM). Boletim da SPM (BSPM).

\section{Abstract}

Our purpose in this work is to recover in the "Boletim da Sociedade Paranaense de Matemática (BSPM)" the papers that reflect directly the influence of the New Math Movement (MMM) in Brazil. At the moment we are studying this movement, that had world repercussion, and occurred in our country mainly at 60's and 70's decades. Our goal here is to present, in a historical perspective, the search's result and analysis the articles that deal with this theme in the BSPM, showing that the MMM reached important national territories, and also reflected in the curricular guidelines in several Brazilian states, particularly in Paraná state. This analysis will be made in all volumes of BSPM, which were the sources used, covering, in this way, a wide and specific object of propagation.

Keywords: New Math Movement. Sociedade Paranaense de Matemática (SPM). Bulletin of SPM.

\section{Introdução}

O Movimento da Matemática Moderna (MMM) foi desencadeado em âmbito internacional na década de 1950. Segundo Pinto (2007), esse movimento atingiu não somente as finalidades do ensino, mas também os conteúdos tradicionais da Matemática, atribuindo uma importância primordial à axiomatização, às estruturas algébricas, à lógica e aos conjuntos.

No Brasil, o Estado de São Paulo é considerado precursor no Movimento da Matemática Moderna, pois foi lá que surgiu o Grupo de 
Estudos do Ensino da Matemática (GEEM), liderado por Osvaldo Sangiorgi, importante educador paulista, o qual foi o principal responsável pela divulgação das ideias do MMM. De acordo com Soares (2005), desde o início da década de 1960 o GEEM procurou difundir as propostas da Matemática moderna pelo país. E Osvaldo Sangiorgi, presidente e porta-voz do grupo, enquanto prestava vários depoimentos à imprensa, também escrevia artigos nos principais jornais de São Paulo, como o Estado de São Paulo e a Folha de S. Paulo. "A imprensa paulista acompanhou de perto todas as atividades do grupo noticiando a realização de cursos, palestras, publicações, eventos e reuniões, além de publicar vários artigos de popularização da Matemática e de orientações para seu ensino" (SOARES, 2005, p. 4).

Entre os objetivos do GEEM se destacava o de coordenar e divulgar a introdução da Matemática moderna na escola secundária ${ }^{1}$, e para isso foram realizados diversos cursos dirigidos aos professores de Matemática em todo o Estado de São Paulo, incluindo sua capital, chegando posteriormente a outros Estados do Brasil.

\section{Origem do movimento da matemática moderna}

Segundo Kline (1976), muitos fatores podem determinar o resultado ruim em determinada atividade de ensino, particularmente no desempenho da disciplina Matemática, por parte de estudantes ou até mesmo de adultos instruídos. Entretanto, os grupos norte-americanos que empreenderam uma reforma no ensino, na década de 1950, concentraram-se no currículo, argumentando que, se esse melhorasse, o ensino da Matemática seria coroado ao êxito.

Em 1952, a Comissão de Matemática Escolar da Universidade de Illinois, presidida pelo professor Max Beberman, começou a preparar

${ }^{1} \mathrm{O}$ ensino secundário era constituído por dois ciclos: ginásio e científico ou clássico, que hoje representaria as quatro últimas séries do ensino fundamental e o ensino médio, respectivamente. 
um novo, ou moderno, currículo de Matemática, que foi aplicado em base experimental na década de 1960.

Nessa mesma década, nos EUA, muitos grupos de professores de Matemática decidem aderir à ideia de criar novos currículos. É interessante observar que, segundo Kline (1976, p. 34), todos esses grupos e/ou autores independentes de compêndios dirigiam-se mais ou menos para a mesma direção. Dessa forma, foram todos descritos pelo termo de "matemáticos modernos" (ou "novos matemáticos").

Segundo Soares (2005), é difícil precisar o momento exato em que as ideias do Movimento da Matemática Moderna começaram a se espalhar pelo mundo. "O certo é que elas, apesar de o movimento ter se desenvolvido de formas diferentes nos vários países em que foi adotada, causaram, por mais de uma década, um grande impacto no ensino da Matemática" (SOARES, 2005, p. 2).

As ideias dos seguidores do Movimento da Matemática Moderna sofreram grande influência da corrente liderada por Nicolas Bourbaki (um francês inexistente com nome grego), pseudônimo coletivo de um grupo de matemáticos franceses em sua maioria, que formavam uma espécie de sociedade secreta, da qual André Weil e Jean Dieudonné foram dois dos mais importantes líderes. Esse grupo começou com a publicação, em 1939, da obra Éléments de mathématiques, em que se estabeleceram relações e semelhanças estruturais entre os diversos ramos da Matemática. O Nicolas Bourbaki foi fundado em 10 de dezembro de 1934 por um grupo de jovens matemáticos provenientes da École Normale Supérieure, de Paris. Os cinco principais fundadores do grupo foram: Henri Cartan, Claude Chevalley, Jean Delsart, Jean Dieudonné e André Weil.

De acordo com Mashaal (2000, apud VALENTE et al., 2007), a visão expressa pelo grupo considerava a Matemática como um edifício dotado de uma profunda unidade, sustentada pela teoria dos conjuntos e hierarquizada em termos de estruturas abstratas, entre elas, algébricas e topológicas.

Assim, o Movimento da Matemática Moderna, de acordo com Soares (2005), surgiu como uma proposta de reforma para o ensino da Matemática que priorizava a unificação da Matemática por meio da teoria dos conjuntos e do estudo da suas estruturas fundamentais. 
No Brasil, as ideias do MMM ganham força a partir da década de 1960. Os principais matemáticos brasileiros, responsáveis pela divulgação das ideias do MMM, foram Osvaldo Sangiorgi, Jacy Monteiro, Omar Catunda e Benedito Castrucci; que foram influenciados por matemáticos franceses do grupo Bourbaki que haviam sido contratados, na década de 1940, pela Faculdade de Filosofia, Ciências e Letras da Universidade de São Paulo. Osvaldo Sangiorgi liderou o primeiro e um dos principais grupos de divulgação das ideias do MMM; o Grupo de Estudos do Ensino da Matemática (GEEM), criado em 1961, na cidade de São Paulo, como mencionamos anteriormente. As atividades desenvolvidas por esse grupo foram diversificadas, segundo Soares (2005), com foco principal na realização de cursos para professores de Matemática na cidade de São Paulo e no interior do Estado, chegando mais tarde, a outros estados brasileiros. Por outro lado, o GEEM também trabalhou na tradução, publicação e divulgação de livros sobre o MMM.

\section{O movimento da Matemática moderna num contexto cultural}

O estudo da história de um movimento, guiado por indivíduos de instituições acadêmicas, em nosso caso particular, o Movimento da Matemática Moderna, pode ser fundamentado na História Cultural, como focaremos adiante. Os trabalhos de Roger Chartier (1990), Norbert Elias (1994) e Peter Burke (2005) nos nortearão.

Assim, as palavras de Carr (1982) nos inspiram a pensar que, quanto mais culturais se tornarem os estudos históricos e mais históricos se tornarem os estudos culturais, tanto melhor para ambos. ${ }^{2}$

As explicações do comportamento de uma dada sociedade são formuladas por meio de um método, segundo Chartier (1990), sustentado pela pesquisa científica, a qual permite que os instrumentos analíticos

\footnotetext{
2 "A história cultural, tal como a entendemos, tem por principal objeto identificar o modo como em diferentes lugares e momentos uma determinada realidade social é construída, pensada, dada a ler" (CHARTIER, 1990, p. 17).
} 
avancem na direção de um modelo interpretativo. Assim, procuramos mostrar que as construções culturais são instrumentos da história cultural, e em particular, da história social. Dessa forma, nesta seção esboçaremos um perfil dos grupos de professores de matemática brasileiros, especificamente do GEEM, no início da década de 1960, privilegiando o percurso dos indivíduos que dele participavam, em suas práticas culturais e de suas atividades cotidianas nos espaços educacionais urbanos.

Os estudos de Trindade e Andreazza (2001), também guiados por Chartier, orientam-nos no sentido de identificar as práticas culturais exercidas por determinado grupo social, atentando para a maneira com que este se apropria dos bens culturais de certo momento histórico. Segundo as autoras, não é, todavia, somente o nível de instrução da população que denota a existência de uma cultura urbana, mas sim a existência de atividades inerentes ao exercício das sociabilidades.

No caso do GEEM, podemos destacar algumas atividades, tais como a programação de eventos científicos e/ou educacionais como cursos para professores do nível secundário em escolas para divulgação do Movimento, tradução de livros que indicavam essa nova proposta de currículo, publicação de artigos em jornais, depoimentos à imprensa a respeito do MMM, programação de palestras e conferências com intuito de divulgação das ideias do Movimento, entre outras.

Roger Chartier (1990), desde os fins dos anos 1980, também questionou a compartimentalização das investigações históricas em estudos sociais, econômicos, políticos e culturais, derivada da noção de que a história está sedimentada em níveis distintos. Para esse autor, as experiências culturais e intelectuais de uma sociedade não denotam um nível separado da experiência social, porém são partes integrantes da realidade histórica. O autor propõe uma mudança na abordagem dos estudos históricos: [...] "da história social da cultura para a história cultural da sociedade". Ele apresenta essa fórmula como descrição de certos "deslocamentos" de interesse por parte de historiadores na década de 1980, especialmente o distanciamento com relação à história social no sentido "duro", do estudo de estruturas como as classes sociais. A ideia da "história 
cultural da sociedade" revela a influência, sobre a Nova História Cultural, do movimento do "construtivismo" na filosofia e em outras disciplinas, da Sociologia à História da Ciência (BURKE, 2005).

Assim, segundo Trindade e Andreazza (2001), aquilo que os historiadores aceitam como estruturas sociais objetivas devem ser vistas como socialmente construídas, já que a sociedade em si mesma é uma representação coletiva.

Desse ponto de vista, "as relações econômicas e sociais não seriam anteriores às culturais, nem as determinam; elas próprias são campos da prática cultural e produção cultural - o que não pode ser dedutivamente explicado por referência a uma dimensão extracultural da experiência" (HUNT, 1992, p. 9).

No entanto, observemos que tratamos de sociedade, ou grupo social, de maneira muito natural, acreditando que seu significado é inerente a seu uso. E dessa forma a usamos corriqueiramente; todavia, questionamos se realmente entendemos seu significado.

A sociedade, como sabemos, somos todos nós; é uma porção de pessoas juntas. Contudo, reportando-nos a Elias, uma porção de pessoas juntas na Índia ou na China forma um tipo de sociedade diferente da encontrada na América ou na Grã-Bretanha, por exemplo.

Segundo Elias (1994), temos certa ideia tradicional do que nós mesmos somos como indivíduos, e temos certa noção do que queremos dizer quando dizemos "sociedade". Procuramos o bem-estar de ambos, ou seja, nosso bem-estar enquanto indivíduo e o do grupo no qual estamos inseridos. Entretanto, para esse autor, só pode haver uma vida comunitária mais livre de perturbações e tensões se todos os indivíduos dentro dela gozarem de satisfação suficiente; e só pode haver uma existência individual mais satisfatória se a estrutura social pertinente for mais livre de tensão, perturbação e conflito. Em nosso estudo, os indivíduos que comporão certo grupo social, no caso o GEEM, também estão inseridos em uma "sociedade", no caso, a classe de professores de Matemática. Dessa forma, elencar algumas características de ambas se faz necessário para interpretarmos ações desses indivíduos ou grupo. 
Considerados num nível mais profundo, tanto os indivíduos quanto a sociedade conjuntamente formada por eles são igualmente desprovidos de objetivo. Nenhum dos dois existe sem o outro. ... "A sociedade é o objetivo final e o indivíduo é apenas um meio", "o indivíduo é o objetivo final e a união dos indivíduos numa sociedade é apenas um meio para seu bem-estar"- eis os gritos de guerra que os grupos em confronto bradam um ao outro, no contexto de sua situação atual, com as pressões e interesses que lhe são transitórios (ELIAS, 1994, p. 18-19).

Buscando encontrar traços para descrever o GEEM nos finais dos anos 1950, deparamo-nos com movimentos que tiveram suas origens em décadas anteriores e alguns elementos de grande importância nas décadas de 1930 e 1940, que vieram a consolidar o Movimento da Matemática Moderna.

Importante é salientar que esse movimento contribuiu para a formação das "sociedades" subsequentes, e dessa forma permite entendermos comportamentos e posições adotados por indivíduos que comporão nosso estudo. E assim inquirimos:

Como é possível que a existência simultânea de muitas pessoas, sua vida em comum, seus atos recíprocos, a totalidade de suas relações mútuas dêem origem a algo que nenhum dos indivíduos, considerado isoladamente, tencionou ou promoveu, algo de que faz parte, querendo ou não, uma estrutura de indivíduos interdependentes, uma sociedade? (ELIAS, 1994, p. 19).

Esse próprio autor nos afirma que, como no caso da natureza, seria bom se só pudéssemos esclarecer nossos atos, nossas metas e nossas ideias do que deve ser se compreendêssemos melhor o que existem, as leis básicas desse substrato de nossos objetivos, a estrutura das unidades maiores que formamos juntos. Para o autor, só assim estaríamos em condições de fundamentar a terapia dos males de nossa vida em comum em um diagnóstico seguro.

Atentemo-nos então à Universidade de São Paulo, a qual atraiu, na década de 1930 e nas décadas subsequentes, muitos professores de 
Matemática, que chegavam de vários pontos do país e de outros países, congregando-se em torno da universidade.

Notamos uma preocupação da instituição acadêmica com relação ao comportamento dos indivíduos que compõem sua sociedade. Não obstante entendemos que esse comportamento também diz respeito às práticas desenvolvidas por esses sujeitos, as práticas culturais. “Todas as práticas, sejam econômicas ou culturais, dependem das representações utilizadas pelos indivíduos para darem sentido a seu mundo" (HUNT, 1992, p. 25).

Essas representações são niveladas pela individualidade de cada pessoa que compõe "sua" sociedade. Aqui entende-se "individualidade" de acordo com Elias (1994), qual seja, uma peculiaridade de suas funções psíquicas, uma qualidade estrutural de sua auto-regulação em relação a outras pessoas e coisas. "Individualidade" é uma expressão que se refere à maneira e à medida especiais em que a qualidade estrutural do controle psíquico de uma pessoa difere da outra.

A sociedade não apenas produz o semelhante e o típico, mas também o individual. O grau variável de individuação entre os membros de grupos e camadas diferentes mostra isso com bastante clareza. Quanto mais diferenciada a estrutura funcional de uma sociedade ou de uma classe dentro dela, mais nitidamente divergem as configurações psíquicas da cada uma das pessoas que nela crescem (ELIAS, 1994, p. 56).

Elias (1994) nos enseja a refletir também sobre o crescimento da especialização das sociedades, asseverando que a trajetória do indivíduo a caminho de se tornar uma pessoa autoconfiante e autônoma torna-se cada vez mais longa e complicada quando a sociedade se especializa, pois aumentam as exigências feitas a seu autocontrole consciente e inconsciente.

Em outras palavras, o desenvolvimento da sociedade rumo a um nível mais elevado de individualização de seus membros abre caminho para formas específicas de realização e de insatisfação, chances específicas de felicidade e contentamento para os indivíduos e formas específicas de infelicidade e incômodo que não são menos próprias de cada sociedade. 
Para sentir um pouco mais dessas práticas sociais e culturais na Universidade de São Paulo (USP), deveríamos buscar no passado uma combinação de fatores que culminaram nesse pólo acadêmico e cultural que a USP almejava se transformar. Assim, voltar aos primórdios do século XX e procurar esmiuçar como se deu o desenvolvimento do ensino superior em Matemática na USP poderia nos trazer indícios de como se constituiu dentro da USP, do Estado de São Paulo e posteriormente em outras regiões do Brasil o Movimento da Matemática Moderna. Sobre isso, trataremos em outros trabalhos futuros.

\section{O Movimento da Matemática Moderna nos boletins da Sociedade Paranaense de Matemática (SPM)}

Como destacamos anteriormente, o Movimento da Matemática Moderna, tanto em nível mundial quanto nacional, foi um movimento de reforma curricular. No Brasil, ele teve início na década de 1960, tendo vigorado até meados da década de 1970 como uma nova proposta para o ensino da Matemática.

Entretanto, já na década de 1950, iniciaram os primeiros congressos no Brasil para discutir o ensino da Matemática. Segundo Miorim (2005), o primeiro evento em nível nacional (I Congresso Nacional de Ensino da Matemática no Curso Secundário) ocorreu na cidade de SalvadorBA, em 1955. Ele representaria uma primeira tentativa de ampliação das discussões acerca do ensino de Matemática brasileiro.

As ideias do Movimento da Matemática Moderna começaram a ser difundidas no segundo e no terceiro congressos, realizados em 1957 e 1959, respectivamente, nas cidades de Porto Alegre, RS e Rio de Janeiro. No entanto, seria no V Congresso, em 1966, realizado em São José dos Campos, São Paulo, que as ideias do MMM estariam no centro das discussões.

Ainda, citando Miorim, a difusão das ideias modernizadoras aconteceria, principalmente, por meio dos cursos organizados pelo 
GEEM, com apoio do MEC e da Secretaria de Estado, e da publicação dos primeiros livros didáticos de acordo com essa nova orientação, a partir da primeira metade da década de 1960.

Dessa forma, detectamos que muitas foram as maneiras encontradas pelos professores simpatizantes desse movimento em divulgar as ideias que dominavam as propostas de reformas no ensino da Matemática. Entre essas, Soares (2005) descreve a imprensa periódica, destacando, entre outras fontes, os jornais do Estado de S. Paulo. Ainda, segundo essa autora, o volume de artigos publicados, nessa época, sugere não ter havido oposição às ideias do MMM e nem à sua divulgação pela imprensa brasileira que publicou livremente todo desenrolar do movimento sem nenhum tipo de objeção.

Nosso propósito é verificar que no Estado do Paraná essas ideias também foram divulgadas. E o veículo que analisaremos são os Boletins da Sociedade Paranaense de Matemática. Esse meio de divulgação é considerado relevante para nós, visto que a Sociedade Paranaense de Matemática é atualmente a sociedade científica de Matemática mais antiga do Brasil em atividade. Para maiores detalhes sobre ela, recomendamos pesquisar A Sociedade Paranaense de Matemática sob um olhar da Educação Matemática (COUSIN, 2007).

Os Boletins da Sociedade Paranaense de Matemática (SPM) foram as segundas publicações da sociedade, a qual havia sido fundada no ano de 1953. Eles se iniciaram no ano de 1958, após algumas publicações dos Anuários (primeiro periódico da SPM).

Por meio de nossa investigação, constatamos que desde a criação desse periódico houve a publicação de três séries dos boletins, divididas da seguinte forma:

$1^{\mathrm{a}}$ série: de 1958 a 1970; 2a série: de 1980 a 1999; 3ª série: de 2002 em diante.

Esse periódico foi publicado, inicialmente, três vezes por ano e, segundo consta em seu primeiro volume, "é o órgão informativo da 'Sociedade Paranaense de Matemática'. Destina-se especialmente a divulgar as atividades da Sociedade e o movimento matemático no Paraná”. 
As palavras do professor Décio Krause nos dão ideia do que representaram a publicação dos boletins da SPM, particularmente os da primeira série.

Então, você veja, o Boletim na época, você vai relatar isso certamente, ele continha muitos assuntos de divulgação em Matemática. Artigos traduzidos de notórios matemáticos, como de André Weil; e outros escritos pelas próprias pessoas que iniciaram esse Boletim, como o professor Newton Costa, e que tinha uma importância enorme, porque naquela época não havia, como há hoje, muitos textos de divulgação Matemática, a gente não encontrava nas livrarias livros como atualmente. Hoje é muito comum que você entre em uma livraria e tenha textos traduzidos para o português, de cientistas sobre os mais variados assuntos, há livros, por exemplo, do Dedekind, dentre outros que tratam de Matemática, e isso contribui muito para a formação dos professores. Então o Boletim tinha esse papel fundamental, além de, evidentemente, conter artigos técnicos, artigos com resultados, artigos nos quais as pessoas tinham a oportunidade de apresentar seu próprio desenvolvimento, sua própria pesquisa em Matemática.

Posteriormente, já nessa fase final, de 1995 em diante, tornou-se muito comum, a partir da década de 1980 principalmente, esse nível de divulgação, e aí nós conversamos certamente com várias pessoas e resolvemos mudar um pouco o enfoque do Boletim. Deixar de ser um texto que se destinava ao Professor de Matemática, que era o que se dizia na apresentação do Boletim, na contracapa, para ser uma revista que pudesse veicular artigos originais de pesquisa em Matemática também, tendo em vista justamente essa possibilidade de você encontrar divulgação de Matemática em outras fontes, o que não era possível no início. Então ele mudou um pouco. E continuou contribuindo! (COUSIN, 2007, p. 151).

Dessa forma, encontramos vários artigos, especialmente na primeira série dos Boletins, que diziam respeito à Educação Matemática, particularmente ao ensino da Matemática, tanto em nível superior quanto em nível secundário. Para maiores detalhes desses trabalhos sugerimos consultar Cousin (2007). 
Especificamente com relação ao Movimento da Matemática Moderna, destacamos duas publicações a seguir:

- $\quad 1^{a}$ série: v. 7, n. 3: outubro de 1964 (Editado por Haroldo Costa): Matemática moderna no ensino - feliz encontro entre a lógica, a psicologia e a pedagogia ${ }^{3}$ (Osvaldo Sangiorgi, professor da Universidade Mackenzie, São Paulo).

- $\quad 1^{\text {a }}$ série: v. 8, n. 1: fevereiro de 1965 (Editado por Serge P. Monoide): Matemática moderna no ensino - feliz encontro entre a lógica, a psicologia e a pedagogia ${ }^{4}$ (Osvaldo Sangiorgi, professor da Universidade Mackenzie, São Paulo).

Esses trabalhos revelam, em parte, a dedicação de Osvaldo Sangiorgi em divulgar o Movimento da Matemática Moderna que se iniciava no Brasil.

Pode-se perceber que, no primeiro artigo, Sangiorgi quer mostrar como foi o desenvolvimento da "Matemática Moderna" nos mais importantes países europeus e nos Estados Unidos e, dessa forma, difundir também esse importante movimento no território nacional.

A chamada Matemática Moderna, que numerosos grupos americanos e europeus têm divulgado com êxito invulgar nas escolas primárias e secundárias (isso porque o ensino superior já gozava desse privilégio) de seus países nos últimos cinco anos, chegou também até nós, graças ao trabalho ininterrupto e eficiente, de quase três anos, do Grupo de Estudos do Ensino da Matemática (GEEM), que congrega em seu seio professores das três Universidades de São Paulo (USP, Mackenzie e Católica) e de outros estabelecimentos de ensino superior do país (SANGIORGI, 1964, p. 76).

${ }^{3}$ Extrato do $1^{\circ}$ Seminário realizado pelo professor Sangiorgi, em 27 de abril de 1964, a convite do Departamento de Educação, da Faculdade de Filosofia da Universidade de São Paulo.

${ }^{4}$ Extrato do $2^{\circ}$ Seminário realizado pelo professor Sangiorgi, no Departamento de Educação, da Faculdade de Filosofia da Universidade de São Paulo. 
Uma via dessa divulgação foi sem dúvida o grupo de estudos GEEM, que, segundo Búrigo, não se limitou à divulgação de propostas de renovação curricular formuladas em outros países. "O apelo local à modernização do ensino de matemática incluía apropriações singulares dessas propostas e sentidos atribuídos à modernização que não coincidiam com aqueles propugnados por organismos governamentais ou por matemáticos europeus e norte-americanos" (BÚRIGO, 2008, p. 43).

Além disso, segundo a mesma autora, no discurso adotado pelo GEEM e, em particular, pelo professor Sangiorgi, a modernização do ensino de Matemática no País era apresentada como necessidade e como urgência.

Como atentamos no primeiro artigo deste trabalho, Sangiorgi busca a apropriação, em território nacional, das propostas de renovação do ensino de Matemática, que eram difundidas por matemáticos e pedagogos europeus e norte-americanos:

Um grupo de gigantes intelectuais - em nome da Psicologia, e comandado por uma dos maiores psicologistas contemporâneos, Jean Piaget; da Lógica Matemática, envolvendo figuras de expressão, como Ewald Beth, Leo Apostel, Wolfe Mays; da Matemática propriamente dita, com a indumentária moderna, introduzida pelo notável Grupo Bourbaki (Jean Dieudonné, André Weil, André Lichnerowicz, Gustavo Choquet, Delsarte, e outros) e da Pedagogia, com os famosos trabalhos de Jacques Rustchmann e supervalorizada por Caleb Gattegno - cuja dedicação integral à transmissão da Matemática fez com que deixasse a cátedra de matemática Superior da Universidade de Londres, para se consagrar ao problema de encontrar a melhor maneira de levar às crianças as verdadeiras mensagens de que é portadora a Matemática vem realizando um extraordinário trabalho de pesquisar o que de comum participa dessas ciências.

Fundamentando cientificamente os resultados obtidos pelo feliz encontro da Psicologia, Lógica Matemática e Pedagogia, conseguiu este Grupo obter informações preciosíssimas, que causaram uma verdadeira revolução no ensino da Matemática de todo o mundo civilizado, principalmente nos cursos primários e secundários, onde os 
jovens estudantes recebiam, via de regra, com certa prevenção "hereditária”, tudo aquilo que em nome da Matemática lhes era oferecido (SANGIORGI, 1964, p. 75-76).

Segundo Búrigo (2008), a defesa da modernização do ensino da matemática assentava-se em dois pilares: a afirmação da necessidade de renovação dos programas de Matemática do secundário, com a aproximação da matemática ensinada nas universidades, o que incluía a adoção de novos conceitos, elementos de linguagem e padrões de rigor; a promessa de um ensino mais acessível e prazeroso, com a superação das dificuldades de aprendizagem e da aversão dos alunos à matemática.

No segundo trabalho apresentado, o professor Sangiorgi estuda, com pormenores, a correspondência existente entre as Estruturas da Inteligência e as Estruturas Matemáticas.

A revelação do universo-mente, pelo Grupo Piaget, pondo em evidência estruturas mentais que estão em correspondência com as estruturas matemáticas apresentadas pelo Grupo Bourbaki exigiu dos pesquisadores educacionais verdadeira revolução do que de matemática se deveria ensinar às crianças, bem como outros métodos de abordagem das diversas disciplinas que participam dos currículos escolares (SANGIORGI, 1965, p. 5).

Segundo Búrigo, o estudo das estruturas matemáticas seria, nos textos de Sangiorgi, o grande eixo da renovação curricular proposta para o ensino da Matemática no ginásio. Esses textos "sugerem a convicção de que a discussão das propriedades envolvidas nas operações mentais seria uma continuidade natural do exercício das operações e da aplicação de suas propriedades pelas crianças" (BÚRIGO, 2008, p. 48).

Havia, pois, uma imperfeição lógica na chamada Matemática tradicional, principalmente por não usar a linguagem que a estrutura mental da criança queria "ouvir" e que só era falada devidamente [...] na Matemática Superior, [...] dentro do espírito bourbakista (SANGIORGI, 1964, p. 77). 
Fácil é ainda perceber, estudando as correspondências existentes entre um sistema mental e um sistema matemático, que o primeiro, numa criança normal, é sempre emulado por meio de "situações matemáticas" criadas pela sua própria estrutura mental (SANGIORGI, 1965, p. 7).

\section{Considerações finais}

Os Boletins da Sociedade Paranaense de Matemática indicam alguns trabalhos, como apresentamos, que revelam a difusão do Movimento da Matemática Moderna em territórios nacionais. Entre esses, notamos que os mais importantes são os de Osvaldo Sangiorgi, considerado, por muitos autores, com muita propriedade, a "estrela-guia" da Matemática Moderna no Brasil.

[...] Se permitiu que Sangiorgi vendesse muitos livros, esse fato é secundário, diante da dinâmica ação educativa do autor que defendia uma introdução gradativa do programa moderno "para evitar malefícios decorrentes de transformações radicais", conseguindo levar, como uma estrela-guia, aos mais recônditos territórios brasileiros, a "boa nova" de um tempo de rápidas e profundas transformações sociais (PINTO, 2008, p. 142-143).

\section{Referências}

BÚRIGO, E. Z. A modernização possível e necessária da Matemática escolar segundo Osvaldo Sangiorgi. In: VALENTE, W. R. (Org.). Osvaldo Sangiorgi: um professor moderno. Brasília: CNPq; GHEMAT, 2008. p. 43-67.

BURKE, P. 0 que é história cultural? Rio de Janeiro: J. Zahar, 2005.

CARR, E. H. Que é história? 3. ed. Rio de Janeiro: Paz e Terra, 1982.

CHARTIER, R. A história cultural: entre práticas e representações. Rio de Janeiro: Bertrand Brasil, 1990. 
COUSIN, A. de O. A. A Sociedade Paranaense de Matemática sob um olhar da educação matemática. 2007. 240 f. Tese (Doutorado em Educação) Universidade Federal do Paraná, Curitiba, 2007.

ELIAS, N. A sociedade dos indivíduos. Rio de Janeiro: J. Zahar, 1994.

HUNT, L. A nova história cultural. São Paulo: M. Fontes, 1992.

KLINE, M. O fracasso da matemática moderna. São Paulo: IBRASA, 1976.

MIORIM, M. Â. Livros didáticos de matemática do período de implantação do Movimento da Matemática Moderna no Brasil. In: CONGRESSO IBEROAMERICANO DE EDUCAÇÃO MATEMÁTICA, 5., 2005, Porto. Actas do V CIBEM... Porto, Portugal: Faculdade de Ciências da Universidade do Porto, 2005.

PINTO, N. B. et al. História do movimento da matemática moderna no Brasil: arquivos e fontes. Guarapuava: Editora da Sociedade Brasileira de História da Matemática, 2007.

PINTO, N. B. Na sala de aula com Osvaldo Sangiorgi. In: VALENTE, W. R. (Org.). Osvaldo Sangiorgi: um professor moderno. São Paulo; Brasília; Osasco: Annablume; CNPq; GHEMAT, 2008. p. 119-144.

SANGIORGI, O. Matemática moderna no ensino: feliz encontro entre a lógica, a psicologia e a pedagogia. Boletim da Sociedade Paranaense de Matemática, Curitiba, v. 7, n. 3, p. 75-79, 1964.

SANGIORGI, O. Matemática moderna no ensino: feliz encontro entre a lógica, a psicologia e a pedagogia. Boletim da Sociedade Paranaense de Matemática, Curitiba, v. 8, n. 1, p. 5-14, 1965.

SOARES, F. dos S. A divulgação da matemática moderna na imprensa periódica. In: CONGRESSO IBERO-AMERICANO DE EDUCAÇÃO MATEMÁTICA, 5., 2005, Porto. Anais... Porto, Portugal: Faculdade de Ciências da Universidade do Porto, 2005.

TRINDADE, E. M. de C.; ANDREAZZA, M. L. Cultura e educação no Paraná. Curitiba: SEED, 2001. 
VALENTE, W. R. et al. Práticas de ontem e de hoje: heranças do Movimento da Matemática Moderna na sala de aula do Professor de Matemática. In ENCONTRO NACIONAL DE EDUCAÇÃO MATEMÁTICA, 9., 2007. Belo Horizonte. Resumo... Belo Horizonte: ENEM, 2007. Disponível em: <http://www.sbem.com.br/files/ ix_enem/Html/minicursos.html>. Acesso em: 31 maio 2010.

Recebido: 15/06/2010

Received: 06/15/2010

Aprovado: 02/09/2010

Approved: 09/02/2010 